\title{
Evaluation of immunocontraceptive vaccine composed of gonadotropin-releasing hormone conjugated with granulocyte-macrophage colony-stimulating factor in male rats
}

\author{
Byung-Joo Park, Yong-Hyun Kim, Hee-Seop Ahn, Sang-Hoon Han, Hyeon-Jeong Go, Joong-Bok Lee, \\ Seung-Yong Park, Chang-Seon Song, Sang-Won Lee, In-Soo Choi* \\ Department of Infectious Diseases, College of Veterinary Medicine, Konkuk University, Seoul 05029, Korea
}

(Received: June 21, 2017; Revised: July 14, 2017; Accepted: July 25, 2017)

\begin{abstract}
Surgical castration performed to reduce male-associated problems results in pain and microbial infections in male animals. Therefore, immunocontraception, which is mediated by the animal's own antibodies against reproductive hormones, has been recommended as an alternative to surgical castration when considering the animal's welfare. In this study, a new immunocontraceptive vaccine composed of six tandem copies of gonadotropin-releasing hormone (GnRH) fused to rat granulocyte-macrophage colony-stimulating factor (GM-CSF) was developed, and its efficacy was evaluated in male rats. Three different doses $(10,50$, and $100 \mu \mathrm{g})$ of recombinant GM-CSF-GnRH protein were injected three times at intervals of two weeks into male rats. The rats vaccinated with three doses of GM-CSF-GnRH produced a significantly higher level of antibodies against GnRH than that in the negative control rats. Severe atrophy of gonads was observed in rats vaccinated with three doses of GM-CSF-GnRH but not in the negative control rats. The results reveal that the new GnRH vaccine conjugated with rat GM-CSF induces efficient immunocontraception in male rats. This formulation of the immunocontraceptive vaccine would be applicable to both domestic and pet male animals.
\end{abstract}

Keywords: immunologic contraception, gonadotropin-releasing hormone, granulocyte-macrophage colony-stimulating factor, rats, vaccines

\section{Introduction}

Surgical castration is routinely performed to prepubertal males of domestic animals for several purposes such as reduction of aggressive behaviors and male-associated odors in meats. However, the practice of surgical castration causes inevitably severe pains and brings unwanted complications such as microbial infections in animals. Therefore, immunocontraception has been suggested as an alternative method to replace the traditional surgical castration [2]. The principle mechanism of immunocontraception is to activate the animal's own immune system to produce antibodies against reproductive hormones [21]. Neutralization of reproductive hormones by the antibodies eventually leads to inhibition of testicular maturation and fertility in male animals $[1,2,8$, $10]$. Gonadotropin-releasing hormone $(\mathrm{GnRH})$ is one of the most important reproductive hormones. Therefore, many immunocontraceptive vaccines are designed to produce antiGnRH antibodies in animals. GnRH composed of 10 amino acids is produced from the hypothalamus. GnRH subsequently stimulates the release of luteinizing hormone (LH) and follicle-stimulating hormone from the anterior pituitary to promote spermatogenesis in male animals [21]. GnRH has low immunogenicity, therefore, carrier or adjuvant materials are needed to enhance the immunogenicity of GnRH. One of those candidate materials is granulocyte-macrophage colony-stimulating factor (GM-CSF) that stimulates the proliferation and differentiation of myeloid progenitors [15]. It also recruits dendritic cells to vaccine-injected sites, which promotes maturation of dendritic cells, and leads to enhanced antigen-specific immune responses [3-5, 14, 17, 20]. For instance, injection of GM-CSF-transfected tumor cells induces a potent local inflammatory reaction mediated by dendritic cells, macrophages, and granulocytes [7, 13]. In addition, recombinant GM-CSF fused or co-injected with various antigens enhances immunogenicity to them $[6,12]$. Recently, DNA vaccines encoding GM-CSF together with pathogenic antigens have been studied to enhance vaccine efficacy against various pathogens $[16,18$, 19]. In this study, we developed a new recombinant GnRH vaccine conjugated with GM-CSF in the purpose of enhancing GnRH immunogenicity. We evaluated the immunocontraceptive efficacy of the GnRH vaccine in male rats.

*Corresponding author

Tel: +82-2-2049-6055, Fax: +82-2-3436-5880

E-mail: ischoi@konkuk.ac.kr 


\section{Materials and Methods}

\section{Expression and identification of GnRH protein con- jugated with rat GM-CSF}

The GM-CSF gene was amplified from the white blood cells of 5-week-old Sprague-Dawley (SD) rats. Blood was collected from the cervical vein, and the white blood cell fraction was isolated by centrifugation with Histopaque-1077 (Sigma, UK). Total RNA was extracted using the RNA-spin Total RNA Extraction Kit (iNtRON Biotechnology, Korea). For the amplification of GM-CSF, primer sequences including specific restriction enzyme sites were as follows: A forward primer 5'-GGA TCC (BamHI) GCA CCC ACC CGC TCA CCC-3' and a reverse primer 5'-AGA TCT (BglII) TTT CTG GAC CGG CTT CCA GC-3'. The amplified GM-CSF gene was cloned into the pGEM-T vector (Promega, USA). One copy of GnRH had the following genetic sequence: 5'GAA CAT TGG TCA TAT GGA CTA CGG CCG GGA-3'. Nucleotide sequences having six copies of GnRH and the restriction enzyme sites of BglII and HindIII at the $5^{\prime}$ and 3' ends, respectively, were synthesized and cloned into a pUC57 vector (Cosmo Genetech, Korea). The six copies of GnRH sequence digested with BglII and HindIII were coligated with GM-CSF, which was digested with BamHI and BglII and cloned into an expression vector, pQE40 (Qiagen, Germany). The recombinant GM-CSF-GnRH protein was expressed in M15 competent cells (Qiagen) and purified in 8 $M$ urea buffer following the manufacturer's instructions (Qiagen). The recombinant protein was identified by SDSPAGE and western blot analysis using a rabbit polyclonal antibody specific to GnRH (Sigma-Aldrich, USA).

\section{Immunization of animals}

Animal experiments were approved by the Institutional Animal Care and Use Committee of Konkuk University (IACUC KU13137). All animals were kept in the animal facility of Konkuk Laboratory Animal Research Center at biosecurity level 2. Specific pathogen-free 4-week-old SD male rats were supplied by a commercial animal supplier (Orient Bio, Korea). A total of 16 male rats were divided into four groups with four rats in each group. Rats in three of the vaccination groups were injected with 10,50 , and $100 \mu \mathrm{g}$ of the recombinant GM-CSF-GnRH vaccine, respectively, and rats in the control group were injected with phosphate-buffered saline. The recombinant GM-CSF-GnRH vaccine was intramuscularly injected to 5-week-old rats, and two boosting injections were given after intervals of 2 weeks. All rats were euthanized by a mixture of zoletil $(50 \mathrm{mg} / \mathrm{kg})$ and xylazine $(5 \mathrm{mg} / \mathrm{kg}) 2$ weeks after the last immunization.

\section{Measurement of anti-GnRH antibody}

Blood samples were collected from the cervical vein of rats prior to each vaccination and euthanasia. The GnRH-specific antibody titer was measured by enzyme-linked immunosorbent assay (ELISA). Briefly, immunoplates were coated with $10 \mathrm{ng}$ of keyhole limpet hemocyanin-conjugated GnRH for $16 \mathrm{~h}$ and then blocked with $5 \%$ skim milk solution for $1.5 \mathrm{~h}$ at $37^{\circ} \mathrm{C}$. The serum samples, which were 40 -fold diluted with $2.5 \%$ skim milk solution, were added to each well of the coated plate and incubated for $1 \mathrm{~h}$ at $37^{\circ} \mathrm{C}$. After three washing steps, a horseradish peroxidase-conjugated antirat immunoglobulin $\mathrm{G}(10,000$-fold dilution in $2.5 \%$ skim milk solution) was added. Tetramethylbenzidine was then added to each well of the plate and incubated for $5 \mathrm{~min}$ for color development. The reaction was stopped by addition of $0.4 \mathrm{M}$ $\mathrm{H}_{2} \mathrm{SO}_{4}$. Optical density was determined at $450 \mathrm{~nm}$ with an ELISA reader.

\section{Histological study}

The testis and epididymis were surgically removed from all rats after sacrifice and their weights were measured. The testis samples were fixed in $4 \%$ neutral buffered formaldehyde and embedded in paraffin. The sections were sliced at $4-\mu \mathrm{m}$ thickness and stained with hematoxylin and eosin. The spermatogonia and spermatocytes were detected in ten seminiferous tubules.

\section{Statistical analysis}

Data were expressed as mean \pm SEM. The experiment results were analyzed for statistical significance using one-way analysis of variance (ANOVA) by GraphPad Prism (ver. 5.00; GraphPad Software, USA). Bonferroni multiple-comparisons test was carried out for post hoc analysis. Statistical analysis for comparing the weights of testis was performed using $t$ test. The level of statistical significance was set at $p<0.05$.

\section{Results}

The recombinant immunocontraceptive vaccine containing six copies of GnRH conjugated with rat GM-CSF was newly developed. The expressed recombinant protein had a molecular weight of $22 \mathrm{kDa}$ as evaluated by SDS-PAGE and west-

$\mathbf{A}$

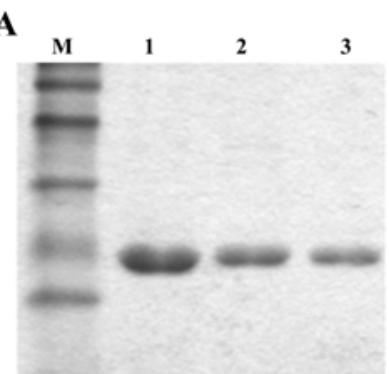

B

Fig. 1. Identification of the recombinant granulocyte-macrophage colony-stimulating factor (GM-CSF)-gonadotropin-releasing hormone $(\mathrm{GnRH})$ protein by (A) SDS-PAGE and (B) western blot analysis. In western blotting, the primary and secondary antibodies used were the rabbit anti-GnRH and goat anti-rabbit immunoglobulin $\mathrm{G}$, respectively. Lane $\mathrm{M}$ is a standard protein marker. Lanes 1, 2, and 3 show 1.55, 0.87, and $0.57(\mathrm{mg} / \mathrm{mL})$ of the GM-CSF-GnRH protein. 


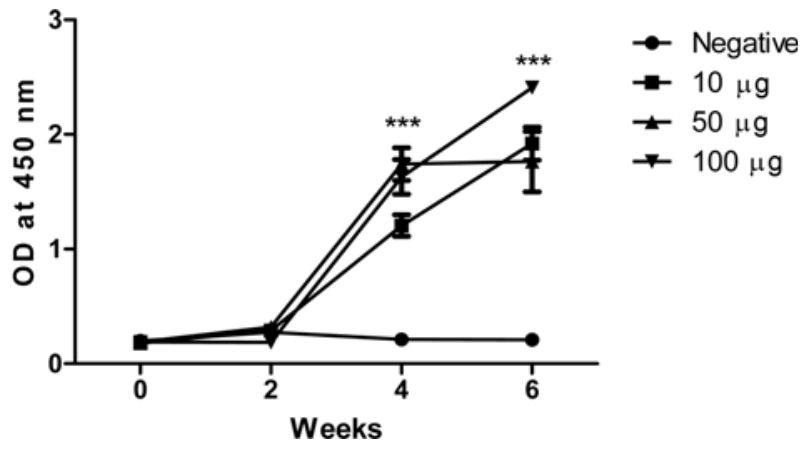

Fig. 2. Measurement of antibody titers in rats vaccinated with three doses of the recombinant GM-CSF-GnRH vaccine. Immunoglobulin $\mathrm{G}$ antibody titers in the serum samples of rats immunized with GM-CSF-GnRH were determined by enzymelinked immunosorbent assay. Antibody titers in rats of the three vaccinated groups were compared with those of the negative control group at 4 and 6 weeks after vaccination $\left({ }^{* * *} p<0.001\right)$.
(A)

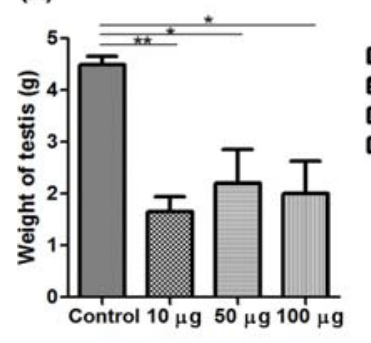

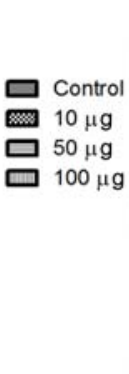

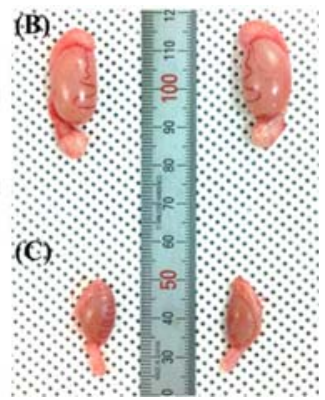

Fig. 3. Weights of testis of rats vaccinated with the three doses of the GM-CSF-GnRH. (A) Mean weights of testis and epididymis of rats in the three vaccinated groups were compared with those of the negative control group at 6 weeks after vaccination $\left({ }^{*} p<0.05,{ }^{* *} p<0.01\right)$. (B) A pair of testis of a rat from the negative control group. (C) A pair of testis of a rat from the group immunized with $100 \mu \mathrm{g}$ of the vaccine.

ern blot analysis (Fig. 1). The anti-GnRH antibody levels were determined by ELISA using serum samples collected from rats in the non-immunized control group and in the three vaccination groups immunized with 10,50 , and $100 \mu \mathrm{g}$ of the recombinant GnRH vaccine. The first immunization could not produce high levels of antibodies, but the boosting injection induced significantly high levels of antibodies in rats of all the immunized groups (Fig. 2). The antibody titers in rats of all the immunized groups were significantly higher $(p<0.001)$ than those of the control group at 4 and 6 weeks after the first vaccination (Fig. 2). The weights of testis and epididymis of rats immunized with $10 \mu \mathrm{g}(p<0.05)$ and with 50 and $100 \mu \mathrm{g}(p<0.01)$ of the GnRH vaccine were significantly lower than those of the negative control group (Fig. 3). Rats in the negative control group and in the immunized groups with 10,50 , and $100 \mu \mathrm{g}$ of the GnRH vaccine showed weights of 4.485 ( \pm 0.162$), 1.657( \pm 0.279), 2.205$ ( \pm 0.648$)$, and $2.002 \mathrm{~g}( \pm 0.629)$, respectively (Fig. 3). These results indicate a $63.0,50.1$, and $55.4 \%$ reduction in the development of

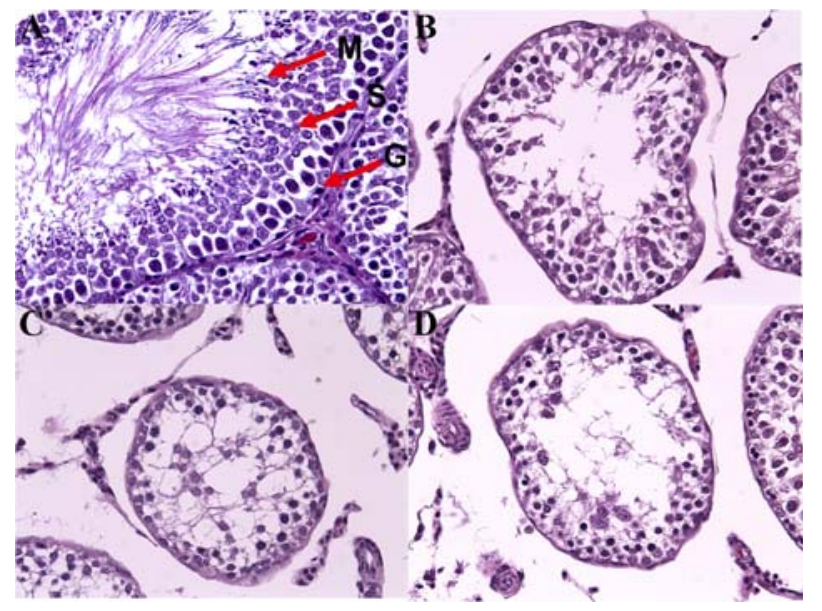

Fig. 4. Testicular tissues of rats immunized with the three doses of the GM-CSF-GnRH. (A) Testicular tissue of a rat in the negative control group showing normal seminiferous tubules, spermatogonia, spermatocytes, and spermatids. (B) Testicular tissue of a rat immunized with $10 \mu \mathrm{g}$ of the vaccine. (C) Testicular tissue of a rat immunized with $500 \mu \mathrm{g}$ of the vaccine. (D) Testicular tissue of a rat immunized with $100 \mu \mathrm{g}$ of the vaccine. $\mathrm{G}$, spermatogonia; M, spermatid; S, spermatocyte. H\&E stain. 400×.

testis in rats vaccinated with the respective concentrations of GnRH vaccine, as compared with the negative control group. Histopathology results demonstrated that the testicular tissues of negative control rats had normal seminiferous tubules and spermatocytes (Fig. 4). However, atrophy of seminiferous tubules and a reduction in the number of spermatocytes was detected in rats of all the immunized groups (Fig. 4). Body weights of rats in all experimental groups were measured after vaccination. Their body weights were not significantly different $(454.4,446.5,446.4$, and $419.2 \mathrm{~g}$ in the negative control and immunized groups with 10, 50, and $100 \mu \mathrm{g}$ of the GnRH vaccine, respectively) ( $p>0.05)$.

\section{Discussion}

Several immunocontraceptive vaccines primarily composed of GnRH have been developed and their effects have been evaluated in various animal models. [9, 11, 21, 22] Since the GnRH is too small to be immunogenic, several highly antigenic materials, such as diphtheria toxoid, tetanus toxoid, or salmonella flagellin have been used as adjuvants [21]. However, the efficiency of these vaccines seemed to vary depending on the animal species and experimental conditions [9]. GM-CSF is a very potent immunostimulatory factor that stimulates immune cells and promotes synthesis of antigen-specific antibodies [20]. Therefore, we developed a new immunocontraceptive vaccine that has GnRH conjugated with rat GM-CSF. In this study, we evaluated the immunogenicity of the recombinant GM-CSF-GnRH vaccine and its inhibitory effects on the maturation of testis in male rats. High levels of $\operatorname{IgG}$ antibodies against $\mathrm{GnRH}$ were 
induced in the rats of all three groups immunized with different doses of the GnRH vaccine. GnRH vaccination also led to a reduction in the size of the testis in the rats of the three immunized groups. Histopathological examination showed that the GnRH vaccine prevented gonad maturation, indicated by under-developed seminiferous tubules and fewer numbers of spermatocytes and spermatogonia in the testicular tissues of immunized rats, which is in accordance with previous reports $[11,22]$. These data imply that antibodies induced by the recombinant GM-CSF-GnRH vaccine cause atrophy of the testis and inhibit reproductive maturation in male rats. This is the first study showing that GM-CSF can be used as an optimal adjuvant protein for the development of an immunocontraceptive vaccine.

In conclusion, the GM-CSF-GnRH vaccine newly developed in this study successfully induced contraceptive effects in male rats through production of anti-GnRH antibodies. In future studies, immunocontraceptive vaccines composed of GnRH conjugated with animal-specific GM-CSF is expected to be applied to domestic and pet male animals.

\section{Acknowledgments}

This study was supported by Korea Institute of Planning and Evaluation for Technology in Food, Agriculture, Forestry and Fisheries (IPET) through Agri-Bio Industry Technology Development Program (or Project), funded by Ministry of Agriculture, Food and Rural Affairs (MAFRA) (Grant No. 316035-3).

\section{References}

1. Adams TE, Daley CA, Adams BM, Sakurai H. Testes function and feedlot performance of bulls actively immunized against gonadotropin-releasing hormone: effect of age at immunization. J Anim Sci 1996, 74, 950-954.

2. Bonneau M, Enright WJ. Immunocastration in cattle and pigs. Livest Prod Sci 1995, 42, 193-200.

3. Casares S, Inaba K, Brumeanu TD, Steinman RM, Bona CA. Antigen presentation by dendritic cells after immunization with DNA encoding a major histocompatibility complex class II-restricted viral epitope. J Exp Med 1997, 186, 1481-1486.

4. Chattergoon MA, Robinson TM, Boyer JD, Weiner DB. Specific immune induction following DNA-based immunization through in vivo transfection and activation of macrophages/ antigen-presenting cells. J Immunol 1998, 160, 5707-5718.

5. Condon C, Watkins SC, Celluzzi CM, Thompson K, Falo LD Jr. DNA-based immunization by in vivo transfection of dendritic cells. Nat Med 1996, 2, 1122-1128.

6. Dela Cruz JS, Trinh KR, Morrison SL, Penichet ML. Recombinant anti-human HER2/neu IgG3-(GM-CSF) fusion protein retains antigen specificity and cytokine function and demonstrates antitumor activity. J Immunol 2000, 165, 5112-5121.

7. Dranoff G, Jaffee E, Lazenby A, Golumbek P, Levitsky H, Brose K, Jackson V, Hamada H, Pardoll D, Mulligan RC. Vaccination with irradiated tumor cells engineered to secrete murine granulocyte-macrophage colony-stimulating factor stimulates potent, specific, and long-lasting anti-tumor immunity.
Proc Natl Acad Sci U S A 1993, 90, 3539-3543.

8. Dunshea FR, Colantoni C, Howard K, McCauley I, Jackson P, Long KA, Lopaticki S, Nugent EA, Simons JA, Walker J, Hennessy DP. Vaccination of boars with a GnRH vaccine (Improvac) eliminates boar taint and increases growth performance. J Anim Sci 2001, 79, 2524-2535.

9. Ferro VA, Khan MAH, McAdam D, Colston A, Aughey E, Mullen AB, Waterston MM, Harvey MJA. Efficacy of an anti-fertility vaccine based on mammalian gonadotrophin releasing hormone (GnRH-I)-a histological comparison in male animals. Vet Immunol Immunopathol 2004, 101, 73-86.

10. Goubau S, Silversides DW, González A, Laarveld B, Mapletoft R, Murphy BD. Immunization of sheep against modified peptides of gonadotropin releasing hormone conjugated to carriers. Domest Anim Endocrinol 1989, 6, 339-347.

11. Jung MJ, Moon YC, Cho IH, Yeh JY, Kim SE, Chang WS, Park SY, Song CS, Kim HY, Park KK, McOrist S, Choi IS, Lee JB. Induction of castration by immunization of male dogs with recombinant gonadotropin-releasing hormone $(\mathrm{GnRH})$-canine distemper virus (CDV) T helper cell epitope p35. J Vet Sci 2005, 6, 21-24.

12. Kass E, Parker J, Schlom J, Greiner JW. Comparative studies of the effects of recombinant GM-CSF and GM-CSF administered via a poxvirus to enhance the concentration of antigen-presenting cells in regional lymph nodes. Cytokine 2000, 12, 960-971.

13. Mach N, Dranoff G. Cytokine-secreting tumor cell vaccines. Curr Opin Immunol 2000, 12, 571-575.

14. Maecker HT, Umetsu DT, DeKruyff RH, Levy S. Cytotoxic $\mathrm{T}$ cell responses to DNA vaccination: dependence on antigen presentation via class II MHC. J Immunol 1998, 161, 6532-6536.

15. Metcalf D. The granulocyte-macrophage colony-stimulating factors. Science 1985, 229, 16-22.

16. Operschall E, Schuh T, Heinzerling L, Pavlovic J, Moelling K. Enhanced protection against viral infection by coadministration of plasmid DNA coding for viral antigen and cytokines in mice. J Clin Virol 1999, 13, 17-27.

17. Porgador A, Irvine KR, Iwasaki A, Barber BH, Restifo NP, Germain RN. Predominant role for directly transfected dendritic cells in antigen presentation to $\mathrm{CD}^{+} \mathrm{T}$ cells after gene gun immunization. J Exp Med 1998, 188, 1075-1082.

18. Sin JI, Sung JH, Suh YS, Lee AH, Chung JH, Sung YC. Protective immunity against heterologous challenge with encephalomyocarditis virus by VP1 DNA vaccination: effect of coinjection with a granulocyte-macrophage colony stimulating factor gene. Vaccine 1997, 15, 1827-1833.

19. Syrengelas AD, Chen TT, Levy R. DNA immunization induces protective immunity against B-cell lymphoma. Nat Med 1996, 2, 1038-1041.

20. Tarr PE. Granulocyte-macrophage colony-stimulating factor and the immune system. Med Oncol 1996, 13, 133-140.

21. Thompson DL Jr. Immunization against GnRH in male species (comparative aspects). Anim Reprod Sci 2000, 60-61, 459-469.

22. Ülker H, Yılmaz A, Karakup F, Yörük M, Budağ C, DeAvila DM, Reeves JJ. LHRH fusion protein immunization alters testicular development, ultrasonographic and histological appearance of ram testis. Reprod Domest Anim 2009, 44, 593-599. 